\title{
Desafios no ensino-aprendizagem de português língua adicional para alunos plurilíngues
}

\author{
Challenges in the teaching-learning of Portuguese as an additional language for \\ multilingual students
}

\author{
Jessiléia Guimarães EIRÓ* \\ Universidade de São Paulo (USP)/Universidade Estadual do Pará (UEPA)
}

RESUMO: Objetivamos refletir acerca da formação do professor, que conhecimentos, competências e estratégias são necessários para capacitá-lo a contribuir para que esses aprendentes plurilíngues estejam aptos a interagir via língua-alvo, atendendo às suas expectativas e necessidades, tendo a seu favor a imersão no contexto de fala do português brasileiro. Usamos como fundamentação teórica as pesquisas de Almeida Filho (2007; 2011), Amado (2012; 2014), Almeida e Judice (2016), Byram; Gribkova; Starkey (2002), Byram; Grundy (2003), Byram et al. (2009), Cenoz (2003), Kramsch, (1998; 2012), Schlater (2014), Santos; Alvarez (2010), Rottava (2008; 2009). Procedemos à pesquisa bibliográfica em Linguística Aplicada e à pesquisa-ação, desenvolvida sala de aula de duas turmas do curso preparatório para o exame de Certificação de Proficiência em Língua Portuguesa para Estrangeiros (CELPE-Bras), na Universidade Federal do Pará (UFPA), 2016 e 2017. Concluímos que o ensino de PLA exige do professor sensibilidade para atender as demandas dos aluno, via o exercício da alteridade, colocando o aluno no centro do processo de descoberta e apropriação da língua e sua(s) cultura(s)-alvo.

Palavras-chave: Português língua adicional. Alunos plurilíngues. Imersão. Pedagogia de línguas.

ABSTRACT: We sought to reflect about which knowledge, skills and strategies teachers need, so they can enable multilingual students to interact using the target language, considering their expectations and necessities, having the immersion in the speech context of Brazilian Portuguese as an advantage. Our theoretical support is based on the studies of Almeida Filho (2007; 2011), Amado (2012; 2014), Almeida e Júdice (2016), Byram; Gribkova; Starkey (2002), Byram; Grundy (2003), Byram et al. (2009), Cenoz (2003), Kramsch, (1998; 2012), Schlater (2014), Santos; Alvarez (2010),

* Professora assistente IV da Universidade do Estado do Pará e doutoranda do Programa de Doutorado em Filologia e Língua Portuguesa- DINTER/ USP/UEPA. E-mail: jjeiro@ gmail.com 
Rottava (2008; 2009). We performed a bibliographic research in Applied Linguistics and an action research, developed in two classes of the preparatory course to the exam of the Certificate of Proficiency in Portuguese for Foreigners (CELPE-Bras) at Federal University of Pará (UFPA), in 2016 and 2017. We concluded that the teaching of Portuguese as an additional language (PAL) requires of the teacher sensitivity to meet the students' demands, by the exercise of alterity, placing the students at the center of the discovery and appropriation of the language and its target culture(s).

Keywords: Portuguese as an additional language. Multilingual students. Immersion. Pedagogy of languages.

\section{Introdução}

Este artigo é parte da pesquisa de Doutorado em andamento, cujo tema é o processo de aquisição/aprendizagem do português língua adicional por alunos plurilíngues em contexto de imersão da língua-alvo. Esses alunos, sujeitos da pesquisa, frequentaram o curso de preparação para o exame de Certificação de Proficiência em Língua Portuguesa para Estrangeiros (CELPE-Bras), nos anos de 2016 e 2017. Eles vêm ao Brasil para participar do Programa de Estudantes-Convênio de Graduação (PEC-G), que oferece a oportunidade de formação superior a estudantes de países em desenvolvimento e com os quais o Brasil mantém acordos culturais e educacionais ${ }^{1}$. Dessa feita, a pesquisa se justifica em face das demandas acadêmicas para enfrentarmos a questão do ensino-aprendizagem de língua estrangeira (LE) e, mais recentemente, o de língua adicional (LA), o que nos levou a buscar as pesquisas concernentes a essa temática e nos conduziu às aulas do curso preparatório para o exame CELPE-Bras, oferecido pela Universidade Federal do Pará (UFPA) para os alunos candidatos a participar do PEC-G, denominados pré-PEC-G.

Os desafios enfrentados por professores no ensino-aprendizagem de português língua adicional (PLA) para alunos plurilíngues têm constituído um tema de pesquisa recorrente no escopo da Linguística Aplicada (LA). Tais desafios se desenham pela necessidade de uma pedagogia de línguas que busque capacitar o professor a atender essa nova demanda, em que se entretecem realidades múltiplas, como a experiência plurilíngue dos aprendentes, o fato de estarem imersos no contexto de fala da língua-alvo, a abordagem de língua como

\footnotetext{
${ }^{1}$ BRASIL. PEC-G. Histórico do Programa. Disponível em:
} http://www.dce.mre.gov.br/PEC/G/historico.php. Acesso: 06 jun. 2016. 
manifestação de cultura, indo além do ensino calcado exclusivamente na exposição do funcionamento estrutural do português, i.e., no ensino de gramática.

Buscamos, portanto, discorrer sobre os desafios postos ao professor no ensinoaprendizagem de PLA, tendo como suporte teórico as pesquisas de Kramsch, (1998; 2012), Byram; Grundy (2003), Cenoz (2003), Sáez (2005), Almeida Filho (2007; 2011), Rottava (2008; 2009), Kemp (2009), Amado (2012; 2014); Santos; Alvarez (2014), Gonçalves (2016). Estabelecemos como objetivo refletir acerca da formação do professor, sobre que conhecimentos, competências e estratégias precisam ser apropriados com vistas a capacitá-lo a contribuir, no contexto de ensino-aprendizagem de PLA, para que esses aprendentes plurilíngues estejam aptos a interagir usando a língua-alvo, atendendo às suas expectativas e necessidades, e tendo a seu favor o fato de estarem imersos no contexto de fala do português brasileiro.

\section{Fundamentação teórica}

Nesta seção, nos propusemos a discorrer, a partir de pesquisa bibliográfica ${ }^{2}$, sobre o ensino de PLA e os desafios enfrentados pelos professores.

\subsection{PLA: uma área em expansão}

Consulta ao site do Observatório da Língua Portuguesa ${ }^{3}$ mostra que há cerca de 262 milhões de falantes do Português como língua nacional, o que a torna a língua mais falada no hemisfério sul, a terceira língua mais falada no hemisfério ocidental e uma das mais faladas no mundo. Do total de falantes, cerca de 209.699.806 ${ }^{4}$ usam a variedade do Português Brasileiro (PB).

Precisamos, portanto, considerar a importância de pensarmos o ensino-aprendizagem de PLA, visto que, de um modo geral, o interesse em aprender PB tem aumentado em função de alguns fatores de ordem econômica e sociopolítica, como, por exemplo, a inserção do Brasil no cenário econômico mundial; os acordos internacionais estabelecidos entre o Brasil e outros países (Mercado Comum do Sul- MERCOSUL, o grupo Brasil, Rússia, China e Índia-

\footnotetext{
${ }^{2}$ Os textos originalmente escritos em Inglês foram por nós traduzidos, assim, o que está presente no corpo do artigo é a tradução em Português.

${ }^{3}$ Disponível em: http://observatorio-lp.sapo.pt/. Acesso: 29 set. 2016.

${ }^{4}$ Disponível em: http://countrymeters.info/pt/Brazil. Acesso: 13 jun. 2016.
} 
BRICS); a efetivação da Comunidade dos Países de Língua Portuguesa (CPLP) e o projeto de criação de uma universidade, onde o Português seria a língua de ensino (ALMEIDA FILHO, 2011); que o PB, de modo particular, é a língua em que os alunos estrangeiros precisam demonstrar proficiência suficiente para serem aprovados no exame CELPE-Bras e, assim, poderem cursar uma graduação em Instituições de Ensino Superior (IES) brasileiras. Isso aponta para a importância do PB no cenário mundial e justifica o seu ensino-aprendizagem institucionalizado enquanto LE para falantes de outras línguas.

Nóbrega (2010, p.1-2) ressalta o aumento na oferta de cursos de Português Língua Estrangeira (PLE) ${ }^{5}$, no Brasil e no exterior, e a demanda por parte de estrangeiros que passam a residir no Brasil:

No tocante a PLE, a expansão tem ocorrido de forma vertiginosa. Basta dizer que há cursos de PLE em instituições do ensino superior nos cinco continentes. No Brasil, a demanda também aumenta a olhos vistos graças ao número de estrangeiros que vêm para o país a trabalho ou como estudantes intercambistas. Mesmo em contexto de imersão, muitos desses estrangeiros buscam um aprendizado formal da língua.

Mais recentemente, as pesquisas em LE têm se expandido e observamos o uso de outras terminologias, as quais objetivam abarcar as novas realidades concernentes ao processo de ensino/aprendizagem de uma L2/LE. Assim é que escolhemos utilizar o termo Língua Adicional (LA). Ressaltamos que a LA pode ser a L3, L4, L5 e assim sucessivamente, dependendo do número de línguas faladas por um dado indivíduo (DE ANGELIZ, 2007, apud ROTTAVA, 2008) ${ }^{6}$. Nossa escolha se justifica pelo fato de os sujeitos da pesquisa, os alunos pré-PEC-G/UFPA que se prepararam para fazer a prova CELPE-Bras em 2016 e 2017, serem falantes de duas ou mais línguas, além de sua língua materna. Assim sendo, o PB passa a constituir mais uma língua adicional a compor o repertório linguístico desses alunos.

\subsection{PLA numa perspectiva multi- e intercultural}

\footnotetext{
${ }^{5}$ Embora usemos a terminologia PLA, faremos uso de PLE se assim tiver sido a escolha do autor citado.

${ }^{6}$ ROTTAVA, L. Aprendizes de PE como L3 ou língua adicional em contexto multilíngue: aspectos gramaticais recorrentes na produção escrita. 2008. Disponível em:

http://www.leffa.pro.br/tela4/Textos/Textos/Anais/CELSUL_VIII/aprendizes_de_pe.pdf. 2008. Acesso: 06 jun. 2016.
} 
De acordo com Rottava (mimeo, apud ROTTAVA, 2008, p. 2, grifo nosso), em se tratando das pesquisas em PLE,

O que predomina nestas pesquisas são discussões que contemplam PLE em contextos de língua estrangeira eou segunda língua (LE/2), cuja base teórica envolve a SLA (Second Language Acquisition). Contudo, pelo crescente campo de ensino de PLE, quer em contexto brasileiro quer em contexto internacional, as características dos aprendizes levam a configurações de ensino e principalmente de pesquisas que passam a focalizar em questões de multilinguismo associadas às LEs que os aprendizes afirmam saber, assim como o contexto de aprendizagem e uso das línguas envolvidas.

Quanto ao conceito de multilíngue/multilinguismo, utilizamos o que se encontra em $\operatorname{Kemp}(2009$, p. 15):

\begin{abstract}
Multilíngue é a pessoa que tem "a habilidade de usar três ou mais línguas, quer em separado quer em vários graus de alternância linguística. Línguas diferentes são usadas com propósitos diferentes e a competência em cada uma varia de acordo com fatores como registro, ocupação e educação" (McArthur 1992: 673; veja também Edwards 1994; Vildomec 1963). Multilíngues podem não ter a mesma proficiência ou controle com relação a todas as línguas que conhecem. O termo 'poliglota' é, também, algumas vezes, usado para descrever pessoas multilíngues. O termo 'plurilíngue' é usado por alguns pesquisadores, incluindo os de tradição francófona, para indicar o indivíduo em oposição ao multilinguismo societal, e o termo 'multilingualidade' é usado para indicar o estado de conhecimento de três ou mais línguas (e.g., Aronin e O Laoire, 2004).
\end{abstract}

Outro conceito caro para compreendermos os desafios enfrentados no ensino de PLA, do qual o professor precisa se apropriar, é o de cultura. Segundo Da Matta (2010, p. 2), “Cultura é, em Antropologia Social e Sociologia, um mapa, um receituário, um código através do qual as pessoas de um dado grupo pensam, classificam, estudam e modificam o mundo e a si mesmas". Em vista disso, cultura "parece ser um bom instrumento para compreender as diferenças entre os homens e as sociedades" (DA MATTA, 2010, p. 3), o que se coaduna com o pensamento aqui defendido de que o ensino de língua como manifestação da cultura (KRAMSCH, 1996, apud SANTOS, 2010, p. 141-142) implica a realidade plurilíngue dos aprendentes como estando imbricada com a experiência pluricultural, o que, por seu turno, implica a "importância de um ensino pluri- e intercultural" (AMADO, 2014, p.728) de línguas. Em vista disso, entendemos que a experiência plurilíngue/o ser plurilíngue facilita a aprendizagem de outras LEs e proporciona a possibilidade de novas experiências com outras culturas-alvo, como preconiza o Conselho da Europa (2001, p.23):

A abordagem plurilinguística ultrapassa esta perspectiva e acentua o facto de que, à medida que a experiência pessoal de um indivíduo no seu contexto cultural se expande, da língua falada em casa para a da sociedade em geral e, depois, para as línguas de outros povos (aprendidas na escola, na universidade ou por experiência 
directa), essas línguas e culturas não ficam armazenadas em compartimentos mentais rigorosamente separados; pelo contrário, constrói-se uma competência comunicativa, para a qual contribuem todo o conhecimento e toda a experiência das línguas e na qual as línguas se inter-relacionam e interagem.

E é nessa perspectiva multi- e intercultural, em se tratando de aulas de PLA, que entendemos a importância do ensino de língua como cultura. Dessa feita, consideramos aqui que ensinar língua como manifestação de cultura propicia aos aprendentes ricas experiências com a língua-alvo, nesse caso o PB, em situações reais de uso, empoderando assim os sujeitos aprendentes a alcançarem seu objetivo, qual seja o de interagir usando a língua que caracteriza a(s) comunidade(s) de fala com que estão em contato.

Daí a necessidade de o professor entender as vantagens da interação construída no processo mesmo de aprendizagem/aquisição da língua estudada, uma vez que o próprio contexto de imersão tão somente resulta em ambiente propiciador da aquisição da língua se o aluno dele usufruir, lançando-se ao uso da língua nas mais variadas situações do dia a dia. Cabe ao professor, orientá-lo, estimulá-lo, levando-o a compreender, inclusive, que o erro faz parte do processo de aprendizagem.

Além disso, é na interação com os nativos que os aprendentes têm a possibilidade de entrar em contato com as diferenças culturais, que constituem experiências extremamente úteis para que vençam o choque cultural vivenciado nos primeiros momentos e que fará parte da convivência a ser enfrentada em ambiente tão diverso na experiência a ser vivida durante a graduação, objeto do PEC-G.

\subsection{PEC-G no Brasil e a experiência de ensino de PLA na Universidade Federal do Pará}

O Brasil não poderia ignorar o interesse de falantes estrangeiros em aprender o PB, assim sendo, ainda na década de 1960, surgiu a ideia de um Programa de Governo que acolhesse os estudantes estrangeiros que quisessem estudar no Brasil. Então, com o fim de regulamentar a situação desses estudantes no país, garantindo-lhes direitos e a unificação das condições de intercâmbio nas universidades, foi lançado em 1965 "o primeiro Protocolo do PEC-G” (BRASIL. PEC-G: Histórico do Programa) ${ }^{7}$, Programa de Estudantes-Convênio de Graduação. Em 12 de março de 2013, o Governo Federal publicou o Decreto $N^{\circ} 7.948$, que dispõe sobre o PEC-G e lhe confere base jurídica, o qual "destina-se à formação e

\footnotetext{
${ }^{7}$ Disponível em: http://www.dce.mre.gov.br/PEC/G/historico.php. Acesso em: 01 out. 2016.
} 
qualificação de estudantes estrangeiros por meio de oferta de vagas gratuitas em cursos de graduação em IES brasileiras" (BRASIL, 2013) .

Cientes da importância dos centros de acolhimento de alunos estrangeiros, em 2006, professores da Faculdade de Línguas Estrangeiras Modernas (FALEM) do Instituto de Letras da Universidade Federal do Pará (UFPA) observaram que muitos intercâmbios com universidades estrangeiras eram frustrados exatamente devido à não oferta de cursos de Português Língua Estrangeira (PLE), o que os levou a tomar a iniciativa de formar

um grupo de estudo visando desenvolver nesta instituição a área de ensino e pesquisa da língua portuguesa para estrangeiros, e capacitar alunos da graduação de Letras (habilitações em alemão, espanhol, francês, inglês e português) para atuarem como professores dos estudantes de programas de intercâmbio como o PEC-G, o CAPES/Brafitec e a Cooperação Brasil-EUA e também para atender a demanda de profissionais estrangeiros que residem no Pará e necessitam aprender o idioma. (SANTOS; BATISTA; SILVA, 2015, p. 1)

Já nesse mesmo ano de 2006, deu-se a criação do Projeto PLE e a UFPA foi credenciada pelo Ministério da Educação (MEC) como posto aplicador do Exame de Proficiência de Português para Estrangeiros, o CELPE-Bras, que ocorre nos meses de abril/maio e outubro, nas IES credenciadas (SANTOS; BATISTA; SILVA, 2015).

Em 26 de outubro de 2018, foi promulgada a Resolução N. 5.110, que institui a Política Linguística da UFPA, a qual, no Capítulo I, Art. $2^{\circ}$ (UFPA, 2018, p. 1-2), apresenta os princípios basilares dessa política linguística, a saber:

I - reconhecimento da diversidade linguística e cultural presente no território brasileiro, mobilizando processos formais ou informais que contribuam para a interação com línguas e culturas variadas, respeitando a diversidade de saberes, culturas, crenças, gêneros e outras diferenças;

II - democratização do acesso à aprendizagem de idiomas, com a promoção de formações destinadas a todos os membros da comunidade da UFPA; 2 Resolução $n$. 5.110 CONSEPE, de 26.10.2018 - Anexo

III - cooperação internacional, com a valorização de processos de formação compartilhados para o intercâmbio de docentes, discentes e servidores técnicoadministrativos em educação;

IV - afirmação da língua portuguesa como língua internacional de educação e de ciência, presente na formação dos estudantes estrangeiros que cursam universidades brasileiras e na comunidade acadêmica internacional;

$\mathrm{V}$ - desenvolvimento integral da pessoa, com a formação no âmbito cognitivo, social e cultural por meio do ensino e aprendizagem de outras línguas;

VI - inclusão, entendendo o ensino e a aprendizagem de idiomas como ações afirmativas uma vez que estas ampliam as oportunidades de inserção social da comunidade interna e externa da UFPA.

Esses princípios vêm, de forma plena, ao encontro das ações relacionadas ao PEC-G e ao atendimento dos alunos participantes do Programa, desde o momento da sua participação

\footnotetext{
${ }^{8}$ Disponível em: www.planalto.gov.br/.../2013/Decreto/D7948.htm. Acesso em: 01 out. 2016.
} 
no curso preparatório para o exame CELPE-Bras até a sua inserção como alunos de cursos oferecidos pela UFPA.

\section{Percurso metodológico}

No que diz respeito ao percurso metodológico, procedemos (i) a uma pesquisa bibliográfica especializada na grande área da Linguística Aplicada, no que tange ao ensinoaprendizagem de língua, tendo como escopo questões de cunho linguístico e social, de línguacultura; e (ii) à pesquisa-ação, a partir da imersão no contexto de sala de aula de duas turmas do curso preparatório para o exame de Certificação de Proficiência em Língua Portuguesa para Estrangeiros (CELPE-Bras), oferecido pela Universidade Federal do Pará (UFPA), 2016 e 2017. Em 2016, segundo semestre, observamos as aulas, fazendo anotações sobre o seu desenvolvimento e tendo como foco o processo de aquisição/aprendizagem dos alunos, suas dificuldades, a busca de informações e sua interação com os professores e colegas etc. Em 2017, ministramos aulas uma vez por semana, quando tivemos um maior contato com os alunos, e coletamos dados com a partir de textos escritos, entrevistas orais, aplicação de questionários, dentre outros instrumentos de pesquisa.

Atualmente, há cinquenta e sete países participando do PEC-G, sendo vinte e cinco países da África, vinte e cinco das Américas e sete da Ásia (BRASIL, 2016). Dentre os sujeitos da presente pesquisa, destacamos a realidade plurilíngue daqueles oriundos de países africanos, como Namíbia, Benin, República Democrática do Congo, Costa do Marfim. Já os alunos vindos da América Central, como Jamaica e Costa Rica, se caracterizam pelo traço da bilingualidade, assim como os que vieram do Timor Leste e Paquistão, por exemplo. O fato de os alunos apresentarem um repertório linguístico tão rico e diversificado demanda do professor de PLA conhecimentos e estratégias de ensino que o capacitem a atender as necessidades desses alunos.

\section{O professor de PLA e os desafios postos}

No contexto atual marcado pelo fenômeno da globalização, em que se acentuam os movimentos migratórios e o contato entre culturas e línguas, vemos emergir a necessidade de

refletirmos sobre os desafios postos ao professor no processo de ensino-aprendizagem de outras línguas. Dentre esses desafios, está o de ensinar português como língua adicional 
(PLA), caso dos alunos pré-PEC-G/UFPA, falantes plurilíngues e que se encontram imersos no contexto de fala da língua-alvo.

Dessa feita, levantam-se questões relacionadas ao ensino de PLA: o que fazer? Como fazer?; e instaura-se, assim, a necessidade de disponibilizar ao professor os resultados de pesquisas na grande área da Linguística Aplicada (RAJAGOPALAN, 2003; ALMEIDA FILHO, 2007; MENEZES; SILVA; GOMES, 2009), que têm refletido acerca do ensino de LE (SANTOS; ALVAREZ, 2010; NÓBREGA, 2010; ALMEIDA FILHO; JÚDICE, 2016); dos conceitos de multilinguismo/plurilinguismo (ROTTAVA, 2008, 2009; KEMP, 2009); de multiculturalismo/pluriculturalismo e educação intercultural (BYRAM; GRUNDY, 2003; SAÉZ, 2005; BYRAM et al., 2009; AMADO, 2014).

Isso tem a ver com a formação do professor de PLA, que precisa privilegiar conhecimentos de Linguística Aplicada, Sociolinguística, Cultura, Psicolinguística, Pedagogia de Línguas etc., para que o professor possa ajudar os alunos a desenvolverem suas competências linguística, comunicativa e intercultural (SÁEZ, 2005).

Em face disso, o que é requerido é que (i) se reflita acerca das demandas atuais do ensino-aprendizagem de línguas no contex to da globalização; (ii) que se capacite o professor a atender a essas novas demandas, em que se entretecem realidades múltiplas: experiência plurilíngue dos aprendentes, imersão no contexto de fala da língua-alvo, abordagem de língua como manifestação de cultura (SÁEZ, 2005; KRAMSCH, 1998; 2012); (iii) que se possibilite ao professor ir além do ensino calcado exclusivamente na exposição do funcionamento estrutural do português, ou seja, no ensino de gramática, e avance para o desenvolvimento das competências a fim de viabilizar a interação usando PLA (CENOZ, 2008; LEFFA; IRALA, 2014), na perspectiva de uma educação intercultural (BYRAM; GRIBKOVA; STARKEY, 2002).

A partir da experiência com as turmas pré-PEC-G do curso preparatório para o exame CELPE-Bras na UFPA, nos anos de 2016 e 2017, observamos que sua condição como sujeitos plurilíngues e imersos no contexto de fala do português, como outra LA, constitui ferramentas a serem usadas pelos professores no sentido de ajudar esses alunos a serem capazes de (i) refletir acerca de sua situação privilegiada; (ii) interagir usando a língua-alvo; e (iii) concretizar suas expectativas e necessidades enquanto indivíduos competentes interculturalmente (SÁEZ, 2005).

Observamos também as dificuldades enfrentadas pelos professores do curso preparatório para o exame CELPE-Bras ao terem que lidar com as especificidades de uma sala de aula como a formada pelos pré-PEC-Gs, em que circulam culturas diversas, com 
repertórios de construção do conhecimento também diversos. Um exemplo, ainda que aparentemente simples, disso é a 'cultura de sala de aula' de boa parte dos alunos vindos de países africanos, nos quais a figura do professor é entendida como sendo de autoridade absoluta, o que implica não terem o hábito de perguntar quando têm dúvidas, reinando, assim, o silêncio durante a aula. Essa atitude, por parte dos alunos, significa respeito, mas, por parte dos professores brasileiros, pode ser entendida como falta de interesse, desmotivação ou ainda falta de dúvidas, deixando transparecer que estão entendendo de forma satisfatória o que está sendo ensinado. Podemos então imaginar as dificuldades experimentadas pelos atores em sala de aula e suas consequências ante a falta de conhecimento e treinamento do professor para mediar tais questões. Tais dificuldades também se repetem no tocante ao ensino da línguaalvo, seja quanto à sua estrutura interna, quanto ao seu uso real.

Ressaltamos que, em nossas interações em sala de aula, quer as formais quer as informais, com essas turmas, percebemos que, sempre que abordamos as questões linguísticas numa perspectiva multicultural, considerando a situação plurilíngue dos sujeitos, houve uma melhor e mais efetiva participação dos alunos nas atividades. Assim, a título de sugestão, propomos intervenções que partam do aluno, seu conhecimento construído, impressões, interesses, dúvidas, experiências e expectativas, num diálogo entre suas línguas-culturas e a língua-cultura-alvo. A partir disso, realçar as semelhanças encontradas e tratar as diferenças do ponto de vista da riqueza própria do gênio humano e não com o estabelecimento de valor melhor e/ou pior -, mas de diferente, diverso.

Para tanto, o professor de PLA precisa ter disponibilizados esses conhecimentos e desenvolvê-los a partir dos construtos teóricos disponíveis, apropriando-se das pesquisas realizadas e fazer da sala de aula um espaço de experimentação, no sentido de embasar seu fazer docente numa pedagogia de línguas que lhe ofereça a possibilidade de uma reflexão contínua acerca dos desafios postos, não apenas no levantamento das dificuldades, mas na construção de respostas que atendam às necessidades de seus alunos.

\section{Considerações Finais}

Buscamos apresentar algumas reflexões acerca da formação do professor, que conhecimentos, competências e estratégias precisam ser apropriados para capacitá-lo a contribuir, no contexto de ensino-aprendizagem de PLA, para que esses aprendentes plurilíngues estejam aptos a interagir usando a língua-alvo, atendendo às suas expectativas e 
necessidades, e tendo a seu favor o fato de estarem imersos no contexto de fala do português brasileiro.

Em nossas intervenções em sala de aula, buscamos colocar em prática o ensino da língua como manifestação de cultura (SÁEZ, 2005; KRAMSCH, 1998; 2012), por entendermos que, na sala de aula de PLA, as discussões/reflexões acerca do funcionamento e uso da língua-alvo em situações reais propiciam maior engajamento entre os atores que dela fazem parte, a saber, alunos e professores. E observamos o estranhamento por parte dos professores-estagiários na condução da aula sob a feição de uma educação que se requer intercultural, de entendimento de que língua e cultura são indissociáveis (SANTOS; ALVAREZ, 2010).

Apresentamos, ainda que sucintamente, o suporte teórico para categorias de análise como PLA numa perspectiva multi- e intercultural, e o ensino-aprendizagem de língua como cultura (KRAMSCH, 1998; 2012).

Para nós, o que fica é a confirmação de que o ensino de PLA exige do professor sensibilidade para atendermos às demandas dos alunos. Sensibilidade que se efetiva pelo exercício da alteridade, que bem poderia ser traduzida como a arte humana de se colocar no lugar do outro; que deve nos levar a colocar o aluno no centro do processo de descoberta e apropriação da língua e sua(s) cultura(s)-alvo, e a nós como seus 'guias', visto já andarmos, como falantes nativos e especialistas que somos, por essas trilhas há mais tempo.

Ressaltamos que os resultados aqui apresentados são de caráter preliminar, visto a pesquisa de doutorado encontrar-se em andamento.

\section{REFERÊNCIAS}

ALMEIDA FILHO, J. C. P. de. Fundamentos de abordagem e formação no ensino de PLE $e$ de outras línguas. Campinas, SP: Pontes Editores, 2011. 130p.

ALMEIDA FILHO, J. C. P. de. Linguística Aplicada, ensino de línguas \& comunicação. Campinas, SP: Pontes Editores e Arte Língua. 2. ed., 2007. 111p.

ALMEIDA, P.; JÚDICE, N. Do novo mundo ao mundo novo: o ensino de português a estrangeiros no Brasil. In: ALVAREZ, M. L. O.; GONÇALVES, L. (Orgs.). O mundo do português e o português no mundo afora: especificidades, implicações e ações. Campinas, SP: Pontes Editores, 2016, p. 265-291. 
AMADO, R. de S. Português Segunda Língua: perspectivas para a pesquisa linguística e o ensino pluri- e intercultural. In: PAPIA 22(2), 2012, pp. 385-398. Disponível em: revistas.fflch.usp.br/papia/article/view/1678. Acesso em: 04 jul. 2016.

AMADO, R. de S. Português Segunda Língua: perspectivas para a pesquisa linguística e o ensino pluri- e intercultural. In: PAPIA v.22, n.2, 2014, p. 385-398. Disponível em: http://revistas.fflch.usp.br/papia/article/view/1678. Acesso em: 04 jul. 2016.

BRASIL. PEC-G. Histórico do Programa. Disponível em: http://PEC-G: Histórico do Programa - Divisão de Temas Educacionais.http://www.dce.mre.gov.br/PEC/G/historico.php. Acesso em: 01 out. 2016.

BRASIL. INEP/CELPE-BRAS. Disponível em: http://portal.inep.gov.br/acoesinternacionais/celpe-bras. Acesso em: 08 jul. 2017.

BYRAM, M.; GRIBKOVA, B.; STARKEY, H. Developing the intercultural dimension in language teaching a practical introduction for teachers. Language Policy Division Directorate of School, Out-of-School and Higher Education. DGIV. Council of Europe Publishing, Strasbourg, $\quad$ France, 2002. 41p. Disponível em: http://www.lrc.cornell.edu/director/intercultural.pdf. Acesso em: 24 ago. 2018.

BYRAM, M.; GRUNDY, P. (Eds.). Context and culture in language teaching and learning. Clevedon: Multilingual Matters, 2003. 111p. Disponível em: https://epdf.tips/context-andculture-in-language-teaching-and-learning.html. Acesso em: 26 maio 2016.

BYRAM, M.; BARRETT, M.; IPGRAVE J.; JACKSON, R.; GARCÍA, M. del C. M., com contribuições de BUCHANAN-BARROW, E.; DAVCHEVA, L.; KRAPF, P.; LECLERCQ, J-M. Autobiography of Intercultural Encounters: Context, Concepts and Theories. Language Policy Division, Council of Europe Publishing, Strasbourg, France, 2009. 28p. Disponível em: http://epubs.surrey.ac.uk/712099/. Acesso em: 20 mar. 2018.

CENOZ, J. The acquisition of additional languages. In: ELIA 8, 2008, pp. 219-224. Disponível em: http://institucional.us.es/revistas/elia/8/12.\%20cenoz.pdf. Acesso em: 28 ago. 2017.

KEMP, C. Defining multilingualism. In: ARONIN, L.; HUFEISEN, B. (Eds.). The Exploration of Multilingualism. Development of research on L3, multilingualism and multiple language acquisition. Amsterdam: John Benjamins Publishing Co, 2009, pp. 11-26. Disponível em: $\quad$ http://npu.edu.ua/!ebook/book/djvu/A/iif_kgpm_Aronin\%20L.\%20The\%20Exploration\%20of\%20Multilingualis m.pdf. Acesso em: 21 jun. 2016. 
KRAMSCH, C. Language and culture. Series Editor H.G. Widdowson. Oxford: Oxford University Press, 1998. 144p.

KRAMSCH, C. Culture in foreign language teaching. In: Iranian Journal of Language Teaching Research 1(1), (Jan., 2013), 2012, pp. 57-78. Disponível em: http://faculty.weber.edu/cbergeson/516/kramsch.2012.pdf. Acesso em: 26 set. 2017.

LEFFA, V. J.; IRALA, V. B. Uma espiadinha na sala de aula. Ensinando línguas adicionais no Brasil. Pelotas: EDUCAT, 2014. 284p. Disponível em: http://www.leffa.pro.br/textos/trabalhos/livro_espiadinha.pdf. Acesso em: 08 mar. 2018.

MENEZES, V.; SILVA, M. M.; GOMES, I. F. Sessenta anos de Linguística Aplicada: de onde viemos e para onde vamos. In: PEREIRA, R. C. M.; ROCA, M. del P. (Orgs.). Linguística Aplicada: um caminho com diferentes acessos. São Paulo: Editora Contexto, 2009, p. 25-50.

NÓBREGA, M. H. Ensino de Português para nativos e estrangeiros: na prática, a teoria é outra. 2010. In: Linha D’Água, São Paulo, n. 23, 2010, pp. 25-40. https://doi.org/10.11606/issn.2236-4242.v0i23, 2010. Disponível em: http://www.revistas.usp.br/linhadagua/article/view/37334/40054. Acesso em: 07 out. 2016.

RAJAGOPALAN, K. Por uma linguística crítica: linguagem, identidade e a questão ética. São Paulo: Parábola Editorial, 2003 (Linguagem 4). 135p.

ROTTAVA, L. Aprendizes de PE como L3 ou língua adicional em contexto multilíngue: aspectos gramaticais recorrentes na produção escrita, 2008. 11p. Disponível em: http://www.leffa.pro.br/tela4/Textos/Textos/Anais/CELSUL_VIII/aprendizes_de_pe.pdf. 2008. Acesso em: 06 jun. 2016.

ROTTAVA, L. Português como língua terceira (L3) ou língua estrangeira (LE) adicional: a voz do aprendiz indicando identidade. 2009. 18p. Disponível em: http://emaberto.inep.gov.br/index.php/emaberto/article/view/2233/2200. Acesso em: 11 set. 2017.

SAÉZ, F. T. En torno a la interculturalidad: reflexiones sobre cultura y comunicación para la didáctica de la lengua. In: Porta Linguarum: revista internacional de didáctica de las lenguas extranjeras. ISSN 1697-7467, $\mathrm{N}^{\mathrm{o}} 4$, 2005, pp. 23-40. Disponível em: https://dialnet.unirioja.es/servlet/articulo?codigo=1709318. Acesso em: 06 set. 2018.

SANTOS, P.; ALVAREZ, M. L. O. (Orgs.). Língua e cultura no contexto de português língua estrangeira. Campinas, SP: Pontes Editores, 2010. 139p. 
UFPA. CONSELHO SUPERIOR DE ENSINO, PESQUISA E EXTENSÃO. RESOLUÇÃO N. 5.110, DE 26 DE OUTUBRO DE 2018. Belém, 2018. Disponível em: http://sege.ufpa.br/boletim_interno/downloads/resolucoes/consepe/2018/5110\%20\%20Propos ta\%20de\%20Resolu\%C3\%A7\%C3\%A3o\%20que\%20institui\%20a\%20Pol\%C3\%ADtica\%20 Linguistica.pdf. Acesso em: 8 fev. 2019. 